\title{
Bovine Antigens and the Formation of Circulating Immune Complexes in Selective Immunoglobulin A Deficiency
}

\author{
Charlotte Cunningham-Rundles, Werner E. Brandeis, Robert A. Good, and \\ NoorBIBI K. DAY, Memorial Sloan-Kettering Cancer Center, New York 10021
}

A B S T RACT We have shown that levels of circulating immune complexes are closely associated with the presence of precipitating antibodies to bovine milk proteins in individuals with selective immunoglobin (Ig)A deficiency. To test whether milk proteins are involved in immune complex formation, sera of seven IgA-deficient individuals were studied for the appearance of complexes after milk ingestion. In three of the seven, an initial fall in the level of complexes was followed by an increasing value, which peaked at 120-150 min. In another three, there was a tendency toward the formation of two peaks of complexes, the first at 30-60 min and the second at 120-150 min after drinking milk. One subject, who had had recent treatment for two separate neoplasms, had a steady level of complexes that did not change during the course of this test. After drinking milk, the molecular weight of the complexes found in the sera of one individual at the start of the milk test fell from $>19 \mathrm{~S}$ to $7-11 \mathrm{~S}$, and in vitro additions of progressively increasing amounts of a mixture of milk proteins or bovine gamma globulin, to sera that contained complexes produced a progressive reduction in the level of complexes detectable. We conclude that the circulating immune complexes found in some patients who lack IgA contain bovine milk proteins and that periodic fluctuation of the molecular weight of such complexes, depending upon antigen ingestion, appears likely. It remains uncertain what effect the chronic circulation of complexes has upon the clinical state of this group of patients.

\section{INTRODUCTION}

Selective immunoglobulin (Ig)A deficiency, which may affect as many as 1 of every 400 individuals in

Address requests for reprints to Dr. C. CunninghamRundles, 1275 York Avenue, New York, N. Y. 10021.

Received for publication 21 September 1978 and in revised form 19 March 1979. certain populations, is one of the most common immunologic disorders (1). A distinctive serologic feature of IgA deficiency is the high frequency $(50-70 \%)$ of precipitating antibodies to cow's milk proteins $(2,3)$. It has been tempting to relate these antibodies to an absence of an effective IgA barrier in the gastrointestinal tract, because it is known that secretory IgA has antibody activity for food antigens, and the presence of this immunoglobulin could presumably prevent adsorption of milk proteins $(4,5)$.

Recent studies in our laboratories have demonstrated that the presence of precipitating antibodies to cow's milk in IgA deficiency is closely correlated with the presence of circulating immune complexes (CIC) ${ }^{1}$ and that a healthy, IgA-deficient individual could be shown to have increasing amounts of CIC for $2 \mathrm{~h}$ after the ingestion of a small amount of milk (3). The studies reported here were performed to extend these observations in both partial and absolute IgA deficiency, and to elucidate the nature of the bovine antigen(s) involved in immune complex formation.

\section{METHODS}

Patients. 16 patients with selective IgA deficiency were chosen for these studies. 15 of these had no history of malignancy, but one patient had been treated for both ovarian and vaginal neoplasms, and was subsequently found to be IgA deficient. No patient had any chronic infections, and all drank cow's milk. Routine blood tests (complete blood count, liver function tests, urea nitrogen, creatinine, antinuclear antibody, anti-DNA antibody, and latex fixation tests), several urinalyses, and a complement profile (total hemolytic complement, C3, and $\mathrm{Clq}$ ) were obtained on all patients. Selected patients also had 24 -h urine collections for protein and creatinine. For these, creatinine clearance was calculated. The immunoglobulin levels of all sera were deter-

${ }^{1}$ Abbreviations used in this paper: BGG, bovine gammaglobulin; BSA, bovine serum albumin; CIC, circulating immune complexes; ELISA, enzyme-linked immunosorbant assay; $\alpha$-lact, $\alpha$-lactalbumin; $\beta$-lact, $\beta$-lactoglobulin; SLE, systemic lupus erythematosus. 
mined by radial immunodiffusion (6), and milk precipitins were detected as described (3).

Quantitation of antibodies to milk proteins. Mixed cow's milk protein (Casec) (Mead Johnson \& Co., Evansville, Ind.) and purified bovine milk proteins (casein, $\alpha$-lactalbumin [ $\alpha$-lact], $\beta$-lactoglobulin [ $\beta$-lact], bovine gammaglobulin [BGG]), and bovine serum albumin (BSA) were purchased from ICN Nutritional Biochemicals, Cleveland, Ohio. Antibodies to milk proteins were quantitated by an enzymelinked immunosorbent assay (ELISA) according to the methods of Engvall and Perlmann (7) with the following modification. Polystyrene tubes were obtained from Falcon Labware, Div. of Becton, Dickinson \& Co. (Oxnard, Calif.) and the bovine antigen solution used to coat the tubes was adjusted to $2 \mu \mathrm{g} / \mathrm{ml}$. In initial studies, sera were diluted $10^{-2}-10^{-5}$ to determine the most efficient dilution for subsequent testing; after the $10^{-3}$ dilution was found optimal, it was used in all subsequent tests. Diluted sera were incubated in the antigen-coated tubes for $5 \mathrm{~h}$. The rabbit anti-human IgG was a $\gamma$-chain specific antisera purchased from Hyland Diagnostics Div., Travenol Laboratories Inc. (Costa Mesa, Calif.). It was purified by $50 \% \mathrm{NH}_{4} \mathrm{SO}_{4}$ precipitation and subsequent passage over DEAE (Bio-Rad Laboratories, Richmond, Calif.) cellulose in $0.01 \mathrm{M} \mathrm{Na}$ phosphate buffer, pH 7.2. The purified protein was lyophilized, dialyzed vs. distilled $\mathrm{H}_{2} \mathrm{O}$, and reconstituted to $5 \mathrm{mg} / \mathrm{ml}$ for conjugation with alkaline phosphatase (Sigma Chemical Co., St. Louis, Mo.) (7). The rabbit anti-human IgG-alkaline phosphatase was incubated in the antigen-coated tubes for $16 \mathrm{~h}$, and after addition of $1 \mathrm{ml}$ of the substrate, $\rho$-nitrophenyl phosphate solution (Technicon Instruments Corp., Tarrytown, N. Y.) (7), the absorbance at $400 \mathrm{~nm}$ was read hourly in a Beckman ACTA CIII spectrophotometer (Beckman Instruments Inc., Fullerton, Calif.) for 4-6h.

Milk ingestion studies. Seven IgA-deficient individuals and three normal controls were given $100 \mathrm{ml}$ of milk to drink after an initial sample of blood had been taken. Blood samples, drawn at 30 -min intervals for $2-3 \mathrm{~h}$, were then studied for the presence of CIC and for detectable bovine milk antigens in agar diffusion of a range of serum dilutions $(1: 1$ to $1: 8)$ against rabbit antisera to bovine $\kappa$-casein, $\alpha$-lact, $\beta$-lact, BGG, and BSA (3).

Circulating immune complexes. CIC were determined in serum samples by the Raji cell radioimmune assay (8). For the analysis of CIC in samples from ultracentrifugation gradients, $25 \mu \mathrm{l}$ of the fractions to be tested were incubated at $37^{\circ} \mathrm{C}$ for $30 \mathrm{~min}$ with $75 \mu \mathrm{l}$ of pooled normal human serum diluted 1:4 with normal saline. Of this mixture, $25 \mu \mathrm{l}$ was removed for analysis in the Raji cell assay.

Sucrose density gradient ultracentrifugation. Sucrose density gradient ultracentrifugation experiments were performed with $10-40 \%$ sucrose in $0.2 \mathrm{M}$ glycine buffer, pH 7.2, and $200 \mu$ l of a serum sample in a Spinco L2-65B Beckman centrifuge (Beckman Instruments, Inc., Spinco Div., Palo Alto, Calif.) at $108,000 \mathrm{~g}$ for $15 \mathrm{~h}$ at $7^{\circ} \mathrm{C}$. In some experiments, the centrifugation was carried out for shorter periods. After centrifugation, $0.25-\mathrm{ml}$ fractions were collected in 5-ml test tubes. Selected fractions were tested for CIC by the Raji cell radioimmunoassay. ${ }^{125}$ I radiolabeled IgM, Clq, and IgG were used as $19 \mathrm{~S}, 11 \mathrm{~S}$, and $7 \mathrm{~S}$ markers, respectively.

In vitro dissociation of immune complexes. Varying quantities of BGG, or mixed milk protein (Casec) were added to the serum samples of one IgA-deficient patient (case 2) obtained before, and $150 \mathrm{~min}$ after milk ingestion. For this test, $25 \mu \mathrm{l}$ of each serum was mixed with $75 \mu \mathrm{l}$ of a $1: 2$, $1: 4,1: 16$, or $1: 64$ dilution of a $1 \mathrm{mg} / \mathrm{ml}$ solution of BGG or mixed milk protein in normal saline. Control sera of $25 \mu \mathrm{l}$ were mixed with $75 \mu$ l of normal saline. After an incubation at $37^{\circ} \mathrm{C}$ for $30 \mathrm{~min}, 25 \mu \mathrm{l}$ of these mixtures was tested as usual for CIC. Two additional sera known to contain CIC obtained from two other IgA-deficient individuals (cases $l$ and 7) 120 min after milk ingestion and two sera known to contain CIC, obtained from two patients with systemic lupus erythematosus (SLE) were also tested with additions of BGG. In control experiments, purified chicken ovalbumin (Sigma Chemical Co.) was added to the sera of case 2 , exactly as described for the bovine antigens.

\section{RESULTS}

Patients. All patients studied had normal routine blood analyses and repeatedly normal urinalyses. The eight patients with the highest levels of CIC had normal 24-h urine quantitations for protein and normal creatinine clearances. Total hemolytic complement, $\mathrm{C} 3$ and $\mathrm{Clq}$, measured in all patients, were found to be normal. Antinuclear antibody, anti-DNA, and latex fixation were negative for all IgA-deficient patients studied here.

Milk precipitins and immune complexes. Table I shows the immunoglobin, milk precipitin, and immune complex data for the IgA-deficient individuals studied. As noted (3), the presence of milk precipitins and CIC in IgA deficiency is closely related. The only exceptions are case 6 , who had no detectable precipitins and in whom the level of complexes was very low, and case 7,

TABLE I

Selective IgA Deficiency

\begin{tabular}{crrrrcr}
\hline Case & Age & IgG* & IgA & IgM & $\begin{array}{c}\text { Milk } \\
\text { precipitins }\end{array}$ & $\begin{array}{c}\text { Immune } \\
\text { complexes }\end{array}$ \\
\hline & $y r$ & $m g / d l$ & $m g / d l$ & $m g / d l$ & & $\mu g$ \\
1 & 19 & 1,134 & 0 & 90 & + & 110 \\
2 & 19 & 1,500 & 0 & 172 & + & 1,520 \\
3 & 33 & 812 & 13 & 312 & 0 & $<16$ \\
4 & 33 & 1,420 & 10 & 105 & + & 320 \\
5 & 35 & 775 & 32 & 55 & 0 & $<16$ \\
6 & 35 & 910 & 31 & 165 & 0 & 32 \\
$7 \S$ & 49 & 1,550 & 0 & 78 & 0 & 240 \\
8 & 35 & 1,574 & 0 & 355 & 0 & $<16$ \\
9 & 59 & 1,760 & 0 & 100 & 0 & $<16$ \\
10 & 5 & 1,940 & 0 & 90 & + & 280 \\
11 & 27 & 2,900 & 0 & 432 & + & 3,200 \\
12 & 44 & 1,318 & 0 & 131 & 0 & $<16$ \\
13 & 43 & 1,640 & 0 & 64 & + & 1,648 \\
14 & 5 & 1,380 & 0 & 112 & 0 & $<16$ \\
15 & 11 & 1,500 & 0 & 120 & + & 832 \\
16 & 12 & 1,760 & 0 & 214 & + & 1,300 \\
\hline
\end{tabular}

* Normal adult immunoglobulin levels are IgG, $800-1,800$ $\mathrm{mg} / \mathrm{dl}$; IgA, 90-450 mg/dl; IgM, 60-280 mg/dl.

$\ddagger$ Measured by the Raji cell radioimmune assay in micrograms equivalent to heat-aggregated $\mathrm{IgG} / \mathrm{ml}$. Levels $<16$ are negative.

$\S$ This patient had been treated for two separate genital neoplasms. 
who had immune complexes but no milk precipitins. (This individual is the patient who had been treated for two previous cancers.)

Quantitation of antibodies to milk. Fig. 1 shows a comparative quantitation of the antibodies found in 12 IgA-deficient sera to the mixture of milk proteins as determined by the ELISA assay. The absorbance at $400 \mathrm{~nm}$ for each serum is given at hourly intervals after the addition of the enzyme substrate.

The five serum samples with milk antibody levels falling below the dashed line can be identified from Table I as samples that lacked milk precipitins and contained very little (case 6) or no CIC (all the rest). The seven sera that produced results falling above the dotted line had precipitins to milk, and all of these sera contained immune complexes.

Antibodies to specific milk proteins. Antibodies to the five main protein constituents of cow's milk (casein, BSA, $\alpha$-lact, $\beta$-lact, and BGG) were then individually quantitated in the sera of eight patients with IgA deficiency who had milk precipitins. Fig. 2 gives the absorbance at $400 \mathrm{~nm}$ after $4 \mathrm{~h}$ incubation

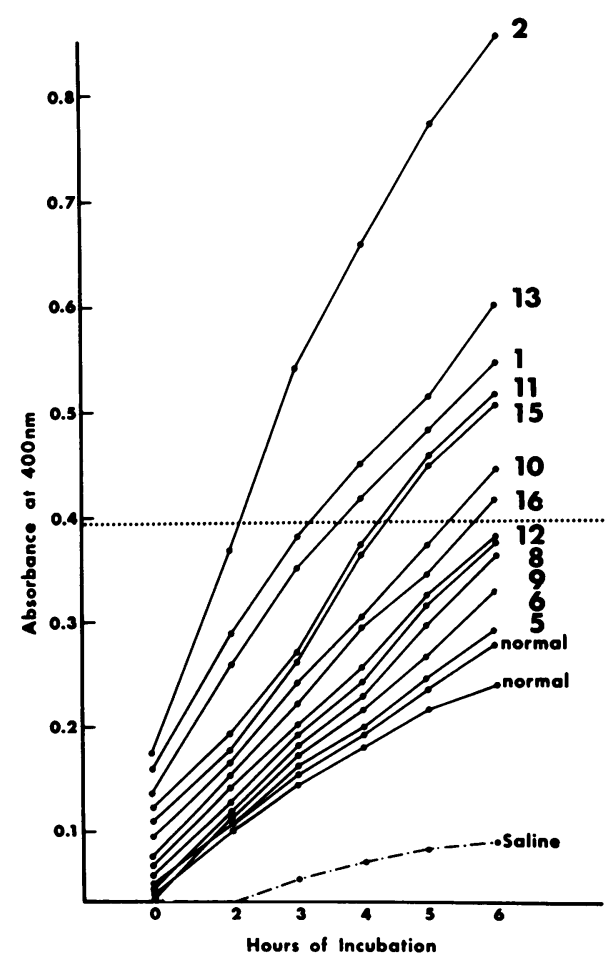

Figure 1 Milk antibody in IgA deficiency. The quantity of milk antibody present in 12 IgA-deficient sera, and 2 normal sera, are compared by an ELISA assay in which the absorbance at $400 \mathrm{~nm}$ was measured at hourly intervals for $6 \mathrm{~h}$ after the addition of the enzyme substrate, $\rho$-nitrophenyl phosphate. The dotted line divides the figure into those sera that had CIC (above this line) and those that did not (below the line).

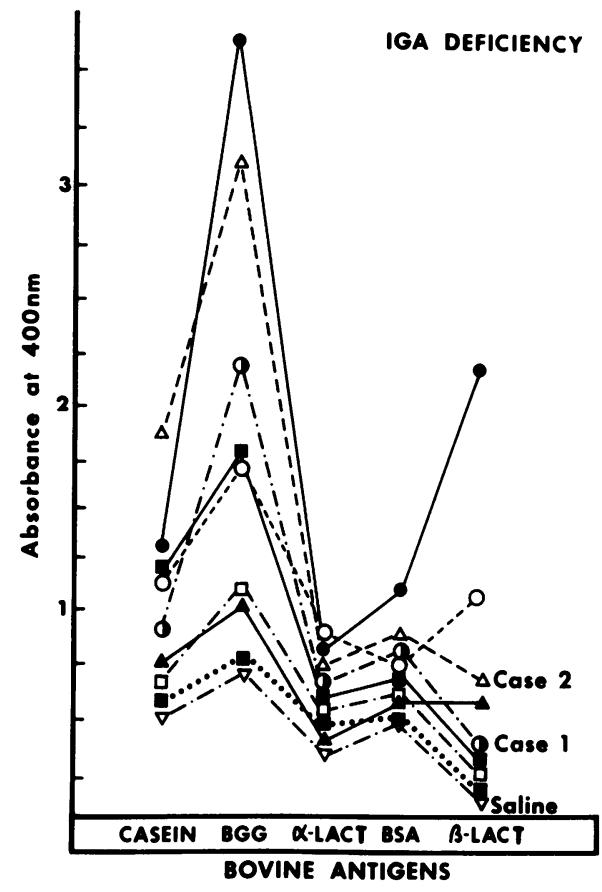

FIGURE 2 Antibody to individual milk proteins. The amount of antibody found in eight IgA-deficient sera directed toward the five major milk proteins, casein, BGG, $\alpha$-lact, $\mathrm{BSA}$, and $\beta$-lact are compared in an ELISA assay by reading the absorbance at $400 \mathrm{~nm}$ after $4 \mathrm{~h}$ of incubation. The results for sera from cases 1 and 2 are marked.

for each serum so that the antibody levels to these proteins can be compared.

The highest absorbance readings for all eight sera were noted for BGG and the second highest readings were for casein; two sera had also increased values for $\beta$-lact. The antibody levels of cases 1 and 2 are indicated.

Milk ingestion studies. Table II shows the results of experiments in which seven of these IgA-deficient individuals (Table I, cases 1-7) drank $100 \mathrm{ml}$ of milk. Note from Table I that cases 1,2 , and 7 have no serum IgA but that cases 3-6 are only partially IgA deficient (13, 10,32, and $31 \mathrm{mg} / \mathrm{dl}$ of IgA, respectively). All but one IgA-deficient individual (case 3 ) had CIC at the start of the test, and in five individuals (all but cases 4 and 7), the CIC fell to undetectable levels (or to a nearly undetectable level in one case) at the 60- to 90 -min interval. After this, in six of the seven IgA-deficient subjects tested, the level of CIC rose again to reach a new peak value, which occurred at 120-150 min after drinking milk. A tendency toward the formation of two "waves" of CIC was noted in three individuals (cases 3,4 , and 6), the first peak of complexes being noted $30-60$ min after milk ingestion. There appeared to be little difference between the first four individuals in the level of CIC formed, but 
TABLE II

CIC after Drinking Milk

\begin{tabular}{|c|c|c|c|c|c|c|c|c|c|c|c|}
\hline \multirow[b]{2}{*}{ Time } & \multirow[b]{2}{*}{ Case ... } & \multicolumn{7}{|c|}{ IgA-deficient } & \multicolumn{3}{|c|}{ Normals } \\
\hline & & 1 & 2 & 3 & 4 & 5 & 6 & 7 & 1 & 2 & 3 \\
\hline $\min$ & & & & & $\mu g$ & & & & & $\mu g$ & \\
\hline 0 & & 184 & 800 & $<16$ & 1,360 & 48 & 22 & 440 & $<16$ & $<16$ & $<16$ \\
\hline 30 & & 192 & 96 & 200 & 368 & 28 & 160 & 480 & 18 & $<16$ & $<16$ \\
\hline 60 & & $<16$ & $<16$ & 240 & 640 & 24 & $<16$ & 200 & 24 & 62 & $<16$ \\
\hline 90 & & 800 & $<16$ & $<16$ & 240 & 320 & 220 & 320 & $<16$ & $<16$ & $<16$ \\
\hline 120 & & 1,280 & 320 & 36 & 272 & 400 & 220 & 320 & 128 & $<16$ & $<16$ \\
\hline 150 & & ND & 680 & 880 & 992 & 328 & 32 & 380 & ND & ND & $<16$ \\
\hline 180 & & ND & 192 & 220 & 122 & $<16$ & ND & ND & ND & ND & $<16$ \\
\hline
\end{tabular}

* Micrograms equivalent to heat-aggregated IgG per milliliter.

$\ddagger$ ND, not done.

for the two individuals having the mildest $\operatorname{IgA}$ deficiency (cases 5 and 6), the amount of CIC formed was less than for cases $1-4$. In case 7 , the level of immune complexes altered little after milk ingestion. (This individual is identified as the one patient studied who had been treated for two recent neoplasms.) Three normal individuals were similarly tested. In two of the three, CIC were detected; in one of these, a level of $128 \mu \mathrm{g} / \mathrm{ml}$ was found $120 \mathrm{~min}$ after drinking milk.

Table III gives the results of agar diffusion of the sera collected from these 10 individuals against rabbit antisera to milk proteins. In case 1 , casein was detectable at $60 \mathrm{~min}$ and in case 2 , at $0,30,60$, and 90 min after drinking milk. (Note from Table III that case 2 had drunk milk about $2 \mathrm{~h}$ before this test was started.) Cases 3 and 5 had no detectable bovine antigens at any interval, but in case $4, \beta$-lact was found in the serum sample collected at $30 \mathrm{~min}$, and in case 7 , $\alpha$-lact, $\beta$-lact, and casein were detectable 30 and $60 \mathrm{~min}$ after milk ingestion. Bovine serum albumin and BGG were not detected in any sera at any time interval. The three normal controls had no milk antigens detectable by this means at any time.

Sucrose density gradient ultracentrifugation. Sucrose density gradient ultracentrifugation experiments using serum samples of case 2 collected before, and at 90 and $150 \mathrm{~min}$ after drinking milk, were performed to determine the molecular weights of the CIC detected at these intervals. Fractions obtained from sucrose gradients were studied for CIC by the Raji cell radioimmune assay, and the molecular weights of the complexes were estimated from the radiolabeled internal markers, IgM, Clq, and IgG for 19S, 11S, and 7S, respectively. In Fig. 3, the amount of CIC is plotted for each fraction studied. Before milk ingestion, case 2 had a large peak $(910 \mu \mathrm{g} / \mathrm{ml})$ of molecular weight complexes $>19 S$, some intermediate-size complexes and a second peak between 7 and 11S (Fig. 3A). At 90 min after ingestion of milk, the high molecular weight peak was reduced to $390 \mu \mathrm{g} / \mathrm{ml}$, whereas the

TABLE III

Agar Diffusion of Sera against Rabbit Antibovine Milk Proteins

\begin{tabular}{|c|c|c|c|c|c|c|c|c|c|c|c|}
\hline \multirow[b]{2}{*}{ Time } & \multirow[b]{2}{*}{ Case ... } & \multicolumn{7}{|c|}{ IgA-deficient } & \multicolumn{3}{|c|}{ Normals } \\
\hline & & 1 & 2 & 3 & 4 & 5 & 6 & 7 & 1 & 2 & 3 \\
\hline \multicolumn{12}{|l|}{$\min$} \\
\hline 0 & & 0 & (casein)* & 0 & 0 & 0 & 0 & 0 & 0 & 0 & 0 \\
\hline 30 & & 0 & casein & 0 & $\beta$-lact & 0 & $\alpha$-lact & $\begin{array}{c}\alpha \text {-lact } \\
\beta \text {-lact }\end{array}$ & 0 & 0 & 0 \\
\hline 60 & & casein & casein & 0 & 0 & 0 & 0 & casein & 0 & 0 & 0 \\
\hline 90 & & 0 & casein & 0 & 0 & 0 & 0 & 0 & 0 & 0 & 0 \\
\hline 120 & & 0 & 0 & 0 & 0 & 0 & 0 & 0 & 0 & 0 & 0 \\
\hline 150 & & ND & 0 & 0 & 0 & 0 & 0 & 0 & ND & ND & 0 \\
\hline 180 & & ND & 0 & 0 & ND & 0 & 0 & 0 & ND & ND & 0 \\
\hline
\end{tabular}

* Case 2 drank milk about $2 \mathrm{~h}$ before this test.

‡ ND, not done. 


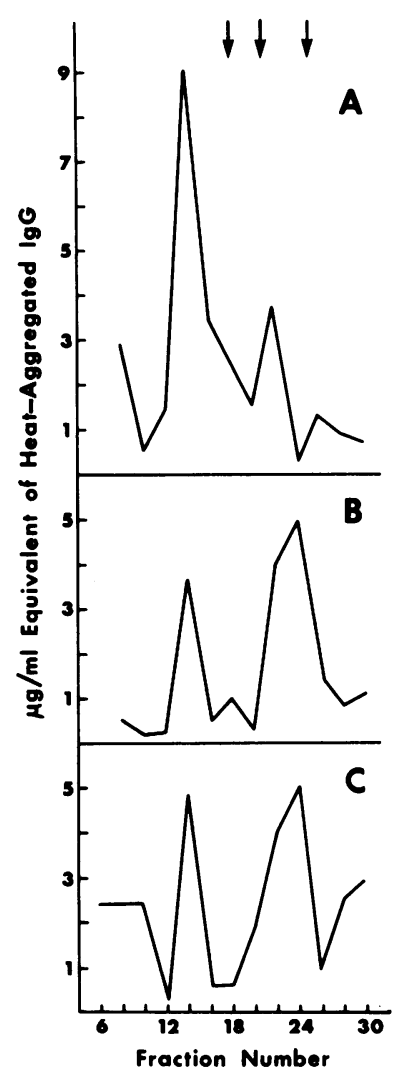

FIgure 3 Sucrose density gradient ultracentrifugation. The results of sucrose density gradient ultracentrifugation of sera from case 2, 0 (A), 90 (B), and $150 \mathrm{~min}$ (C) after drinking $100 \mathrm{ml}$ milk. Fractions from each gradient were analyzed for CIC; molecular weight markers, seen at the top from the left are IgM (19S), Clq (11S), and IgG (7S).

region of 7-11S was found to be larger than in the initial sample, and shifted toward the $7 \mathrm{~S}$ region (Fig. 3B). In the 150-min sample the high molecular weight peak had increased to $490 \mu \mathrm{g} / \mathrm{ml}$ (Fig. 3C).

Antigen addition experiments. Bovine gamma globulin, or the mixture of milk proteins (Casec) was added in increasing amounts to aliquots of the serum samples of case 2 collected before the milk ingestion study, and 150 min after drinking milk. The quantity of immune complex detected in each sample was then determined. Fig. 4 shows the results obtained after the addition of BGG to the 150-min serum, as compared to a similarly treated serum from a patient who has SLE. As increasing amounts of BGG were added, smaller amounts of immune complexes were detectable in the serum of case 2 , whereas there was no change in the quantity of complexes detected in the SLE sera. The level of CIC was found to be $67 \%$ reduced (from 630 to $150 \mu \mathrm{g}$ equivalent to heat-aggregated $\mathrm{IgG} / \mathrm{ml}$ ) by this addition. The serum of case 2 drawn at the start of the milk study gave similar results to

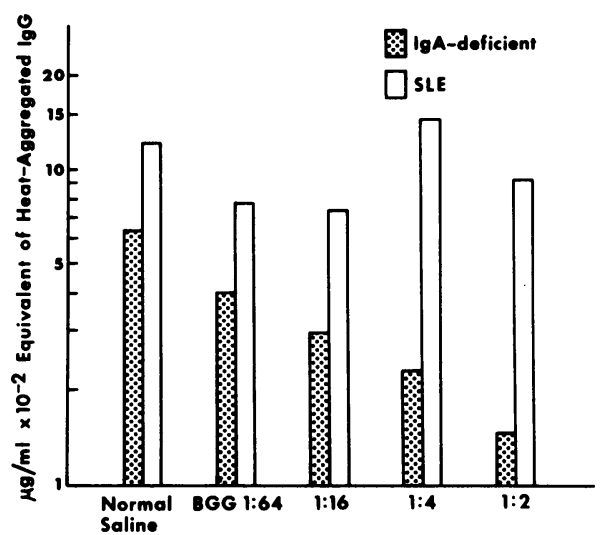

FIgURE 4 Identification of an antigen in the CIC. To five aliquots of sera from case 2, 150 min after drinking milk, was added progressively increasing amounts of BGG. The quantity of CIC detected in each sample is given here (dotted bars) and compared to similarly treated serum from a patient with SLE (open bars).

that of the 150-min sample (not shown), whereas that of another patient with SLE (in whom complexes were $4,000 \mu \mathrm{g} / \mathrm{ml}$ ) were also unchanged after the addition of BGG. Further additions of BGG to either the initial or 150-min serum sample of case 2 caused no further reduction in the amount of detectable complex, and additions of chicken ovalbumin to these sera in the manner described for BGG also caused no reduction in the level of complexes (results not presented). Similar additions of the mixed milk proteins caused an $\cong 80 \%$ reduction in the level of CIC found in the $150-\mathrm{min}$ sample (results not presented). As for BGG, further additions of the mixture of milk proteins caused no further reduction in the level of CIC detectable.

Fig. 5 shows the results of two additional antigen

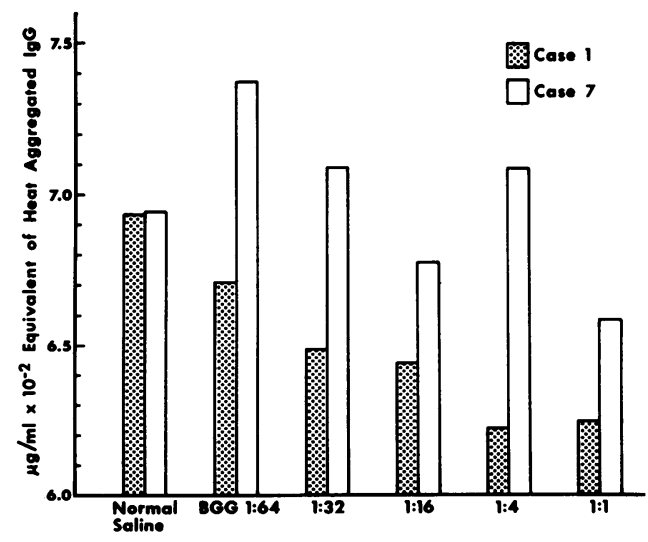

FIGURE 5 Antigen identification experiment. To five aliquots of sera of cases 1 and 7, taken 120 min after drinking milk, was added progressively increasing amounts of BGG. The quantity of CIC detected in each sera is given here (case 1, dotted bars; and case 7, open bars). 
addition experiments in which BGG was added in increasing amounts to the sera of case 1 and case 7 drawn $120 \mathrm{~min}$ after milk ingestion. As increasing amounts of BGG were added to the serum of case 1 , smaller amounts of immune complexes were detected, whereas there was no similar decrease in the level of CIC detected in the serum of case 7 .

\section{DISCUSSION}

We recently noted a strong correlation between the presence of milk precipitins and CIC in selective IgA deficiency (3). Because the titer of the precipitins and the amount of complex detected were found roughly proportional, it seemed possible that milk proteins could be involved in complex formation. In the present studies we have investigated this unusual phenomenon: first, by studying the bovine protein $(\mathrm{s})$ that stimulate the production of these antibodies; second, by comparing individuals with differing degrees of IgA deficiency; third, by an analysis of the kinetics of immune complex formation; and fourth, by a preliminary identification of the antigen(s) contained in the complexes.

A study of the total anti-milk antibody in these IgAdeficient individuals showed that the sera that contained precipitating antibodies to milk in agar diffusion had the greatest amount of antibody in an ELISA assay. This is in agreement with Peterson and Good (9) and Buckley and Dees (2), who observed that sera that contained milk precipitins also had the highest titers in an hemagglutination assay. Furthermore, sera that contained CIC and those that did not (with the exception of case 6 , who had a very low level of complexes, and case 7 , who had been treated for cancer) could be distinguished on the basis of the relative amount of anti-milk antibody, further suggesting that milk proteins could be involved in these antigen-antibody complexes.

On investigating the amount of antibody found to individual bovine milk proteins, we found that eight IgA-deficient sera containing milk precipitins had the largest amount of antibody directed toward BGG. Although it seemed possible that this result could have been ascribed a hypothetically more effective antigen coat formed by BGG in the ELISA assay, the fact that individual sera did vary in their responses to the different antigens (including BGG) and the fact that 12 bovine milk-drinking infants studied separately were found to have the majority of anti-milk antibody directed against the casein fraction, indicates that BGG is the most antigenic fraction for IgA-deficient individuals who have milk precipitins. This conclusion is in agreement with the findings of other investigators who have shown that bovine IgM is actually the major antigen in bovine serum for individuals with selective IgA deficiency (10).
Testing the hypothesis that bovine proteins are involved in the formation of CIC, we found that six of the seven IgA-deficient individuals tested appeared to form CIC after drinking milk and that the amount of complex found in the sera of four more severely IgA-deficient individuals exceeded that found in the sera of two individuals with less severe IgA-deficiency.

One individual who has no serum IgA had no convincing change in the level of CIC after milk ingestion; this individual had been recently treated for two separate genital neoplasms and in fact she had (unlike the others) no prior medical history suggestive of IgA deficiency (i.e., sinopulmonary infections, pneumonia, gastrointestinal complaints, etc.). Her IgA deficiency was discovered incidently. Because sera of more than $50 \%$ of patients with cancer have been found to have CIC (11), we conclude that her complexes are more likely to be related to this condition than to the formation of complexes containing bovine antigens. It is interesting to observe that multiple bovine antigens were detectable in her serum after milk ingestion, but that the level of CIC did not increase after drinking milk. This fact can be correlated with the observation that in an ELISA assay she had less antibody to bovine antigens than the other IgAdeficient patients studied. Because milk-drinking adults appear to gradually lose the capacity to form antibody to bovine proteins (12), it is possible that this $49-y r-o l d$ woman (the oldest patient tested in the milk ingestion studies) does not form CIC that contain bovine proteins simply because of relative milk antibody deficiency. If this explanation is correct, it indicates that although CIC may be common in some individuals with IgA deficiency for the first four to five decades, antigenemia without complex formation may predominate after this point. Preliminary information obtained from studies of our older IgA-deficient patients indicates that this interpretation may be correct.

We predicted that if the antigen-antibody complexes found in IgA-deficient patients contained bovine proteins, then such complexes might become temporarily undetectable after milk ingestion because of a displacement of the equilibrium to favor antigen excess. For five of the seven IgA-deficient individuals, the initiallypresent complexes did indeed fall to undetectable levels (or to a nearly undetectable level in one patient) 60-90 min after milk ingestion.

In addition, molecular studies on the sera of case 2 indicate that this hypothesis may be correct. This individual had ingested milk about $2 \mathrm{~h}$ before this study, and in the initial serum sample a faint amount of casein was detectable in agar diffusion; the CIC level at this time was $800 \mu \mathrm{g} / \mathrm{ml}$. If these complexes contained milk antigens, further milk ingestion would be expected to cause a reduction in the molecular 
weight; in fact this was observed, as the initial complexes were greater than $19 \mathrm{~S}$, but $90 \mathrm{~min}$ after milk ingestion, the majority of complexes were between 7 and $11 S$ in molecular weight.

To test this phenomenon in vitro, bovine antigens were added to the initial and 150-min serum sample collected from case 2. Bovine gamma globulin, or a mixture of milk proteins, when added to these sera, produced a progressive, although differing degree of decrease in the level of detectable CIC, whereas no reduction in CIC was observed in sera collected from two SLE patients nor did ovalbumin produce this effect in the sera of case 2. Similar additions of BGG to the serum of case 1 (taken $120 \mathrm{~min}$ after milk ingestion) also caused a marked decrease in the level of detectable CIC, although such additions did not alter the level of complexes detectable in the serum of case 7. This latter result supports our conclusions that the complexes present in the serum of this patient may be related to the presence of cancer, rather than to ingested food antigens.

We questioned why BGG alone was able to affect such a major decrease in the level of CIC in both cases 1 and 2 . For case 2, a $67 \%$ decrease was produced by BGG and an $\cong 80 \%$ decrease was produced by the mixture of milk antigens. As mentioned above, BGG has previously been shown to be the most important antigen for at least some individuals with IgA deficiency (10), and in fact from ELISA antibody studies, BGG was indeed the major antigen for both cases 1 and 2. Therefore, the large decreases in detectable immune complexes produced by BGG additions does not seem unreasonable. It remains uncertain why the addition of mixed milk protein did not make all the complexes disappear. We cannot exclude the strong possibility that other kinds of antigens are also involved in excessive absorption from the gastrointestinal tract and subsequent complex formation in IgA deficiency. However, from these experiments we do conclude that the majority of CIC found in these individuals do contain bovine proteins, and that BGG was the predominant antigen in the complexes of the patients studied here.

Although it is recognized that the agar diffusion method used here to demonstrate antigenemia is relatively insensitive, its use still demonstrates two main points: $(a)$ the fact that very large amounts of antigen may be absorbed in the absence of $\operatorname{IgA}$ and (b) the time intervals during which such absorption occurs. This information may then be correlated with the timing of complex formation. The inability to detect BGG by this method is most likely caused by its low concentration in milk; of the five proteins studied here, BGG is present in the lowest concentration $(2-3 \%$ of the total milk protein [13]). For a full investigation of the antigenemia that occurs in these patients after drinking milk, more sensitive methods of detecting each of the major milk antigens will be required, and these are underway.

Studies on immune complex disease in animals have shown that the molecular size of the immune complex is an important determinant in the pathological outcome $(14,15)$. Although very large immune complexes, formed as a result of extreme antibody excess, are readily removed by phagocytes and the reticuloendothelial cells, complexes of intermediate size, which are formed when antigen and antibody are nearer equivalence, are associated with the inflammatory lesions of chronic immune complex disease $(14,15)$. If the studies described here can be generalized, the CIC present in IgA deficiency probably undergo considerable daily molecular weight fluctuation caused by periodic antigen absorption. At least some of these complexes would have the intermediate molecular weights associated with pathogenic potential.

It has been clearly established from the extensive work of Walker and Isselbacher (16) that the gastrointestinal tract is normally permeable to macromolecules and that oral administration of food antigens results in both systemic and local immunity (17). In some individuals with selective IgA deficiency, it appears that unimpeded, chronic milk antigen absorption can promote high levels of specific serum antibodies, which, as further antigen absorption occurs, is followed by the development of CIC.

It is unknown at present what pathologic significance the periodic circulation of immune complexes in IgA deficiency may have. Individuals who lack IgA have an increased incidence of connective tissue disease (18), malignancies (19), autoantibody production (19-21), and allergic disorders (19). Whether the circulation of immune complexes is related to the development of these diseases is unknown, because it has not been established that IgA-deficient individuals who have milk precipitins (and therefore, by our data, CIC), have more of these associated illnesses. In our own group of IgA-deficient individuals, we have searched for evidence of chronic immune complex disease. Renal damage (as assessed by frequent microscopic examination of the urine, urine protein, serum urea nitrogen, serum creatinine, and creatinine clearance) has not been found in our patients thus far, and in fact, renal abnormalities have not, in general, been noted by others as a particular feature of selective IgA deficiency (21). The lack of such abnormalities in the face of the undoubted chronic circulation of antigen-antibody complexes, is unexplainable at present. We have, however, noted that arthritic complaints and radiographic abnormalities of the joints, are more common in the IgA-deficient group who have formed 
milk precipitins. This may indeed be their manifestation of immune complex disease, but more direct evidence must be obtained before this correlation can be firmly drawn.

The methods described here appear to be very useful for studying the dynamics of formation and dissolution of naturally-occurring immune complexes. Because both in vivo and in vitro experiments are practical, this previously undescribed phenomenon provides a unique model system for the study of CIC in humans. Of particular importance are the in vitro antigen addition experiments, which appear to provide a means of identifying antigens in an immune complex. This kind of experiment may have broad applicability in the investigation of the immune complexes that appear in other diseases.

\section{ACKNOWLEDGMENTS}

We wish to thank Ms. Theodosia Zacharczuk for skillful technical assistance; Mrs. Jean Nimkin, Ms. Anne Banker, Mrs. Alice Martin, and Ms. Chloe Goosens for coordination and for nursing care; and Doctors Senih Fikrig, Ben Frank, Sudhir Gupta, Fred Siegal, Stanley Schwartz, and Elizabeth Smithwick for referral of patients. Dr. Harold Farrell and Dr. Ulrich Hämmerling kindly gave us antisera to bovine proteins.

This work was aided by U. S. Public Health Service grants CA 08748, CA 18488, A1-11843, AI 19286, ACS IM-ICS, NS 11457, The Zelda R. Weintrab Cancer Fund, The Express Forwarding and Storage Fund, and Deutsche Forschungsgemeinschaft $\mathrm{Br} 660-1$.

\section{REFERENCES}

1. Koistinen, J. 1975. Selective IgA deficiency in blood donors. Vox Sang. 29: 192-202.

2. Buckley, R. H., and S. C. Dees. 1969. Correlation of milk precipitins with IgA deficiency. N. Eng. J. Med. 281: 465-469.

3. Cunningham-Rundles, C., W. E. Brandeis, R. A. Good, and N. K. Day. 1978. Milk precipitins, circulating immune complexes and IgA deficiency. Proc. Natl. Acad. Sci. U. S. A. 75: 3387-3389.

4. Katz, L., H. M. Spiro, and T. Herskovic. 1968. Milk precipitating substance in the stool in gastrointestinal milk sensitivity. N. Engl. J. Med. 278: 1191-1194.

5. Heremans, J. F., and P. A. Crabbé. 1968. IgA deficiency: general considerations and relation to human disease. In Immunologic Diseases in Man (Birth Defects Original Article Series) D. Bergsma and R. A. Good, editors. The National Foundation, New York. 4: 298-310.
6. Mancini, G., A. O. Carbonara, and J. F. Heremans. 1965. Immunochemical quantitation of antigen by single radial immunodiffusion. Int.J. Immunochem. 2: 235-254.

7. Engvall, E., and P. Perlmann. 1972. Enzyme-linked immunosorbent assay. J. Immunol. 109: 129-135.

8. Theofilopoulous, A. N., C. B. Wilson, and F. J. Dixon. 1976. The Raji cell radioimmune assay for the detection of immune complexes in human sera. J. Clin. Invest. 57: 169-182.

9. Peterson, R. D., and R. A. Good. 1963. Antibodies to cow's milk proteins: their presence and significance. Pediatrics. 31: 209-221.

10. Huntley, C. C., J. B. Robbins, A. D. Lyerly, and R. H. Buckley. 1971. Characterization of precipitating antibodies to ruminant serum and milk proteins in humans with selective IgA deficiency. N. Engl.J. Med. 284: 7-10.

11. Tishima, H., H. Wanebo, C. Pinksy, and N. K. Day. 1977. Circulating immune complexes detected by ${ }^{125} \mathrm{I}-\mathrm{Cl}_{\mathrm{q}}$ deviation test in sera of cancer patients. J. Clin. Invest. 59: $1134-1142$.

12. Kornblatt, P. E., R. M. Rothberg, P. Minden, and R. S. Farr. 1968. Immune responses of human adults after oral and parenteral exposure to bovine serum albumin. J. Allergy. 41: 226-236.

13. Whitney, R. M. L., J. R. Brunner, K. E. Ebner, H. M. Farrell, R. V. Josephson, C. V. Morr, and M. E. Swaisgood. 1976. Nomenclature of the proteins of cow's milk. J. Dairy Sci. 59: 785-815.

14. Cochrane, C. G., and D. Koffler. 1973. Immune complex disease in experimental animals and man. Adv. Immunol. 16: $186-264$.

15. Dixon, F. J. 1973. Immune complex diseases. J. Invest. Dermatol. 59: 413-415.

16. Walker, W. A., and K. J. Isselbacher. 1974. Uptake and transport of macromolecules by the intestinal tract. Prog. Gastroenterol. 67: 531-550.

17. Walker, W. A., R. Cornell, L. M. Davenport, and K. J. Isselbacher. 1972. Macromolecular absorption mechanism of horseradish peroxidase: uptake and transport in adult and neonatal rat intestine. J. Cell. Biol. 54: 195-205.

18. Cassidy, J. T., A. Burt, R. Petty, and D. Sullivan. 1969. Selective IgA deficiency in connective tissue diseases. N. Engl. J. Med. 280: 257.

19. Ammann, A. J., and R. Hong. 1973. Selective IgA deficiency. In Immunologic Disorders in Infants and Children. E. R. Stiehm and V. Fulginiti, editors. W. B. Saunders Company, Philadelphia, Pa. 199-214.

20. Ammann, A. J., and Hong, R. 1970. Selective IgA deficiency and autoimmunity. Clin. Exp. Immunol. 7: 833-838.

21. Buckley, R. H. 1975. Clinical and immunologic features of selective IgA deficiency. In Immunologic Diseases in Man (Birth Defects Original Article Series). D. Bergsma and R. A. Good, editors. The National Foundation, New York. XI: 134-142. 